CORRECTION

\title{
Correction to: A note on the three methods of item analysis
}

\author{
Seock-Ho Kim ${ }^{1}$ (D) Allan S. Cohen ${ }^{2} \cdot$ Hyo Jin Eom ${ }^{3}$
}

Published online: 3 April 2021

(C) The Behaviormetric Society 2021

\section{Correction to: Behaviormetrika https://doi.org/10.1007/s41237-021-00131-1}

In the original publication of the article, Appendix A was published incorrectly.

The correct appendix is provided below:

\section{Appendix A}

A hypothetical Item 44 based on Wainer (1983).

The original article can be found online at https://doi.org/10.1007/s41237-021-00131-1.

Seock-Ho Kim

shkim@uga.edu

1 Department of Educational Psychology, University of Georgia, 325 Aderhold Hall, Athens, GA 30602-7143, USA

2 University of Georgia, Athens, USA

3 Korea University, Seoul, Korea 

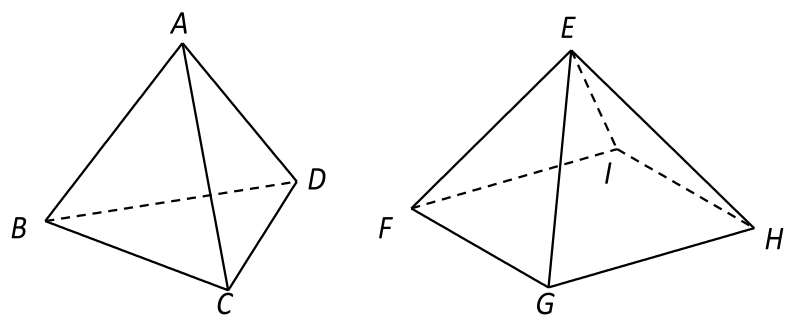

44. In pyramids $A B C D$ and $E F G H I$ shown above, all faces except base $F G H I$ are equilateral triangles of equal size. If face $A B C$ were placed on face EGF so that the vertices of the triangles coincide, how many exposed faces of the original pyramids would the resulting solid have?
(A) Five
(B) Six
(C) Seven
(D) Eight
(E) Nine

The original article has been corrected.

Publisher's Note Springer Nature remains neutral with regard to jurisdictional claims in published maps and institutional affiliations. 